\section{¿Espectador en acción?: representación e identificación del pueblo/masa en El Chacal de Nahueltoro}

Is There an Active Audience? : representation and Identification of The People/Mass in El Chacal de Nahueltoro

Catalina Donoso

Boston University, Romance Studies Department, Boston, USA

catadonoso@gmail.com

Resumen - El Chacal de Nahueltoro es uno de los filmes claves de la cinematografía nacional en general y del llamado Nuevo Cine Chileno en particular. El presente trabajo intenta explorar las contradicciones y tensiones entre la representación del pueblo y la apelación al espectador -encarnado a su vez en la imagen de "pueblo" desplegadas en la película. El análisis del concepto de "pueblo" y del rol del espectador cobra mayor complejidad en el contexto de un cine comprometido con el cambio social, que pone en relieve la participación activa del espectador y su relación directa con el filme.

Palabras clave: espectador, recepción, Nuevo Cine Chileno, pueblo.

Abstract - El Chacal de Nahueltoro is not only one of the most important films in the Chilean Cinema as a whole, but it is particularly a key work in the so called New Chilean Cinema. The present article attempts to explore the contradictions and tensions between people's representation and the audience appeal portrayed at the same time in the people's image displayed in the film. The analysis of the concept of "the "people" and the role of the spectator become more complex in a context where cinema is conceived as an element of social change, foregrounding the audience's active participation and its close relation to the film itself

Keywords: Spectator, Reception, New Chilean Cinema, The People.
En 1967 se llevó a cabo en la ciudad de Viña del Mar lo que se ha considerado un hito fundacional en la configuración de uno de los movimientos más importantes en la historia del cine chileno y también latinoamericano: el Primer Festival Internacional de Cine de Viña del Mar. Dicho encuentro constituyó la reunión oficial inaugural de una serie de propuestas estético-políticas que venían desarrollándose en los últimos años en la región. Fue el primero de carácter internacional y realizado en suelo latinoamericano, en el que participaron representantes de Argentina, Bolivia, Brasil, evidentemente Chile, Cuba, y Uruguay. Ya desde los años cincuenta una nueva corriente de lenguaje cinematográfico había comenzado a perfilarse en varios países de Latinoamérica, la que dio origen a una escuela que marcó radicalmente la producción fílmica de estos países. Influenciada fuertemente por movimientos europeos como el Neorrealismo o la Nueva Ola francesa, pero alerta sobre todo a la conformación de una voz propia que diera cuenta de los conflictos sociopolíticos del subdesarrollo y el neocolonialismo, esta corriente dio a luz numerosos discursos o manifiestos que a pelaban al compromiso político que su arte debía promover ${ }^{1}$. Se trataba no sólo de mostrar la realidad precaria y marginal latinoamericana, sino sobre todo de movilizar a los espectadores hacia la acción: este cine era el de la liberación, el de la revolución, y fue conocido con el nombre genérico de Nuevo Cine Latinoamericano, aunque en los distintos países tuviera también su rótulo específico.

Si bien se trata de un movimiento ampliamente estudiado y visitado por la crítica, en Chile, a causa del Golpe de Estado que tuvo lugar en septiembre de 1973, buena parte de la producción cinematográfica que surgió en torno a estos postulados en el período de la Unidad Popular (1970-1973) y en el período inmediatamente anterior, y también su estudio, fueron interrumpidos durante los años de la dictadura, a causa de la censura y la represión ideológica. En efecto, desde hace algunos años la producción artística y cultural de esta etapa ha estado siendo rescatada a través de trabajos de recopilación que intentan poner en relieve las creaciones y políticas culturales llevadas a cabo; sin embargo, la mayor parte de la bibliografía disponible en torno a la historia del cine chileno es más bien de carácter descriptivo o compilatorio que material crítico. En los últimos años se ha despertado un creciente interés por cubrir este espacio crítico, escenario del cual el presente trabajo forma parte.

Enmarcado en un período de particular conmoción política en el continente a partir de la Revolución Cubana en 1959, el Nuevo Cine Chileno vivía también en su entorno inmediato una época de transformaciones. Importantes medidas de corte social como la Reforma Agraria y el fortalecimiento de los partidos de izquierda a través de una coalición (la Unidad Popular) que, tres años más tarde del mencionado Festival de Viña del Mar, llevó a la Presidencia al primer mandatario socialista elegido democráticamente, eran el telón de fondo de este movimiento cultural. Sin desconocer la relevancia que el encuentro internacional antes citado tuvo para la cinematografía chilena, Miguel Littin, director de filme conocido como $E$ l Chacal de Nabueltoro ${ }^{2}$, distingue, sin embargo, el año siguiente al festival como el punto de despegue del nuevo cine en el país:

Entre los manifiestos y planteamientos teóricos más importantes que surgieron tras este período y que desarrollan los principales lineamientos de este Nuevo Cine Latinoamericano se cuentan El manifiesto de Santa Fe (1962) de Tín (1896-1983) alemana crítico de cine e historiadora del cine alemán Su libro más importante es Ia pantalla demoníaca (1965), estudio estético, ideológico e histórico del referido movimiento cinematográfico. El título original de la película es: En cuanto a la infancia, andar regeneración y muerte de Jorge del Carmen 

However, the year which marked the public arrival of Chilean cinema was 1968 -four filmes were presented that year, the first works of four new directors: Tres tristes tigres by Raúl Ruiz, Helvio Soto's Caliche Sangriento, Valparaíso mi amor by Aldo Francia and El Chacal de Nahueltoro, which I made myself. [...] Of course, this whole process radicalized itsel further with the electoral success of Salvador Allende, and you then saw an intensification of production, particularly in shorts ${ }^{3}$ (Chanan, 1976: 54).

Y no es errado sostener que, en términos de producción y estreno de películas, 1968 fue un año crucial, pero no es menos cierto que el encuentro internacional de cine dio pie a un diálogo de tipo teórico, a un encuentro de ideas y posiciones sobre el cine que no se había dado con tal fuerza antes en Chile. De hecho, no existen textos teóricos contundentes desarrollados en el período ${ }^{4}$ que puedan equipararse a los que como ya señalé se elaboraron en Cuba, Brasil y Argentina. Tal vez el único documento que puede ser considerado como tal es "El manifiesto de los cineastas de la Unidad Popular". Sin embargo, dicho texto, tal como su nombre señala, se reduce a un manifiesto que define, en trece "declaraciones", la postura de quienes a él adscriben, y no puede equipararse a los ensayos teóricos antes mencionados, los cuales, por lo demás, lo preceden.

Miguel Littin, junto a Sergio Castilla, fue co-autor de dicho manifiesto, el cual fue firmado y dado a conocer tras el triunfo de la candidatura de Salvador Allende, que instauró el primer gobierno socialista en Chile. En este trabajo de investigación quiero analizar la obra más reconocida de Littin en cuanto a la apelación y representación de un espectador potencialmente activo que en ella se despliega, y las contradicciones que dicha representación desarrolla dentro de sí misma y con relación a los postulados que podemos desprender de este manifiesto y de otros textos que definen la posición del Nuevo Cine respecto al rol del espectador.

El Chacal de Nabueltoro ha sido reconocida como uno de los tres filmes fundacionales del cine chileno 5 . Obtuvo el Premio de la Crítica Chilena en 1968, representó a Chile en el Festival de Cine de Berlín en 1970 donde obtuvo el premio OCIC. Distinguida, entonces, dentro y fuera del país por su aporte artístico, fue también un éxito sorprendente de público para la época, tratándose además de una producción no pensada con fines comerciales y en el contexto de una industria fílmica apenas incipiente, llevó cerca de medio millón de espectadores a las salas de cine. Littin explica el fenómeno de audiencia atribuyéndolo a

Valenzuela Torres, quien se hace llamar también José del Carmen Valenzuela Torres, Jorge Sandoval Espinoza, José Jorge Castillo Torres, Alias el Campano, el Trucha, el Canaca, el Chacal de Nabueltoro. on presentras eño, todas correspondientes a las óperas primas de cuatro nuevos directores: Tres tristes tigres de Raúl Ruiz, Caliche Sangriento de Helvio Soto, Valparaíso mi amor de Aldo Francia y El Chacal de Nahueltoro, escrita y dirigida por mí. [...] Por supuesto, este proceso se radicalizó aún más con la victoria electoral de Salvador Allende, y en aquel entonces se pudo percibir una intensificación de la producción, electoral de Salvador Allende, y en aquel entonces se pudo percibir una inten
particularmente en cortos" (Chanan, 1976: 54). [Trad. Texto original en inglés].

particularmente en cortos" (Chanan, 1976: 54). [Trad. Texto original en ingles]. Experimental de la Universidad de Chile) sostiene que: "éramos los hermanos chicos en todo esto y los que discutían e iban a la vanguardia eran los cubanos, brasileños y argentinos y aparte que en Chile había poca elaboración en el terreno teórico, no teníamos una crítica seria, casi ninguna; en cambio allí está Viany de Brasil, Gettino y Solanas en Argentina y en Cuba, Julio Garcia Espinosa, ideólogo del Cine Imperfecto; estaban llenos de sugerencias y estímulos para reflexionar sobre el cine y renovar; en Chile no, no conozco textos teóricos sobre lo que debía ser el cine chileno, salvo el manifiesto de la Unidad Popular que era algo

Junto a Valparaíso mi amor, de Aldo Francia y Caliche Sangriento, de Helvio Soto. que: "we were dealing with a theme which deeply roused the interest of the popular Chilean class" 6 (Chanan, 1976: 55). Llama la atención, de todas formas, que una película realizada desde las pautas del "cine imperfecto" y no del gusto comercial-masivo, aún cuando su temática despertara interés en las clases populares, moviera en tal magnitud al público.

El Chacal de Nabueltoro está basada en un hecho de sangre acaecido en los alrededores de la ciudad de Chillán a comienzos de la década del '60. Un afuerino ${ }^{7}$ iletrado y alcoholizado dio muerte a una mujer y sus cinco hijas. Durante el proceso judicial estuvo preso en la cárcel de Chillán por casi tres años y en el período de su reclusión fue alfabetizado, evangelizado y transformado en un hombre civilizado que: "se da más cuenta de la vida" ". Una vez dictada la sentencia de muerte, y tras el rechazo del Presidente de la época a otorgarle el indulto, el hombre fue fusilado. El hecho suscitó una interesante controversia en torno a la pena de muerte, el sistema judicial, la marginalidad y otros temas de tipo socio-político que la cinta recoge y expone.

The film reconstructs the crime and the public attention that it elicited in order to disclose that both the crime and the criminal are the products of a corrupt society that invokes the bourgeois judicial apparatus against those who have been deliberately and completely marginalized from bourgeois society ${ }^{9}$ (López, 1990: 413).

Aunque fue escrita en apenas tres días, el período previo de recopilación del material duró más de dos años. En la realización, cuyo rodaje tomó entre 2 y 3 meses en precarias condiciones, podemos constatar dicho trabajo de investigación, ya que el esqueleto del filme está engarzado en documentación auténtica del caso (entrevistas, el expediente judicial, diarios de la época) que lo vincula estrechamente al neorrealismo italiano y al cinema verité en cuanto a la incorporación de técnicas narrativas propias del cine documental. Este diálogo o utilización de los recursos del documental en el argumental, es también un atributo que lo enlaza con la búsqueda de veracidad y compromiso que se gestaba en el cine de la época. El género documental, muchas veces considerado "el pariente pobre del séptimo arte" (Paranaguá, 2003: 16), fue reivindicado por esta nueva corriente de cine y su compromiso político con la realidad. En El Manifiesto de Santa Fe escribe Fernando Birri:

¿Cómo da esa imagen, el cine documental? La da como la realidad es y no puede darla de otra manera $[\ldots]$

La denuncia, la enjuicia, la critica, la desmonta. Porque muestra las cosas como son y no como querríamos que fueran $[\ldots]$

Conclusión: ponerse frente a la realidad con una cámara y documentarla, documentar el subdesarrollo (Paranaguá, 2003: 456).

Si bien la cinta recurre a diversos registros narrativos, al menos dos de ellos se inscriben

"Tratamos un tema que despertó profundamente el interés de la clase popular Chilena" (Chanan, 1976: 55). [Trad. Texto original en inglés].

Un afuerino es un individuo que no tiene hogar ni trabajo fijo y que vaga por las haciendas -fundos en Chilebuscando ocupaciones temporales que le permitan tener acceso a comida y a casa.

Estas son palabras del propio preso, registradas en una entrevista que la misma película documenta.

"El filme recrea el crimen y la atención pública que este provocó, con el objetivo de develar que tanto e crimen como el criminal son productos de una sociedad corrupta que pone al aparato judicial burgués en completamente marginados de la sociedad burguesa" (López, 1990: 413). [Trad. Texto original en inglés]. 
en los procedimientos del documental. Varios pasajes, con el testimonio registrado en el acta del juicio y la reconstitución de la escena del crimen como voz de fondo, se filman al estilo de la "recreación" de hechos, una práctica que el documental utiliza frecuentemente y que nos habla sobre una fusión de géneros, en que el registro documental echa mano a la ficción para optimizar sus recursos. Por otra parte, las escenas que incluyen la ficcionalización del reporteo del crimen (uno de los personajes principales es el periodista que fueron ampliamente populares antes de la masificación de la televisión y que marcaron la producción documental cubana germinal. Tampoco es un dato menor que el montajista de El Chacal, Pedro Chaskel (a cuyo trabajo se atribuye en buena medida la calidad estética del filme), sea también un reconocido documentalista, ni tampoco que algunas de las locaciones utilizadas para la realización sean los escenarios reales en los que tuvieron lugar los sucesos (la escena del crimen, la celda de la cárcel de Chillán). La crítica ha coincidido en que la película, en términos de estilo, puede dividirse en dos partes (López, 1990: 416). La segunda parte es la que se considera más convencional con relación al lenguaje cinematográfico y la primera, la más arriesgada en cuanto a montaje y uso de la cámara y la que combina con mayor libertad los recursos a los que he hecho alusión.

Sin embargo, y pese a su utilización de técnicas documentales, El Chacal se define a sí misma como una película de ficción, no como un documental: una historia basada en hechos reales, pero cuya estructura, a pesar de la inclusión de estos registros, sigue siendo la de un filme argumental. Debo hacer notar, por ejemplo, que si bien se utilizan escenarios reales y buena parte de los textos son transcripciones de los documentos legales o periodísticos, no se presentan en el filme imágenes de archivo (la detención del implicado por ejemplo o la reconstitución del crimen), ni se elaboran secuencias fotográficas a partir de material documental. Quiero situar entonces a El Chacal de Nabueltoro, pieza inaugural de lo que se dio en llamar el Nuevo Cine Chileno, en el registro del cine argumental, pero en diálogo con las técnicas del género documental, género que como vimos, fue puesto en relieve en el período a causa de su rango de testimonio y su labor de denuncia.

Una vez sentadas estas bases que definen el material con el que voy a trabajar, mi punto de inflexión tiene relación con el intercambio que la película establece con el espectador implícito inscrito en la película, cómo lo representa y de qué manera apela a él. Quiero establecer tres enfoques iniciales para el desarrollo de la reflexión. En primer lugar, estamos ante un filme que, como vimos, pertenece a una corriente mayor para la que el cine está al servicio de una causa que excede los límites de lo puramente estético, la causa revolucionaria, liberadora, que debe despertar las conciencias y llamar a la acción. En este sentido, el espectador más que un mero espectador, es un potencial actor. Seguramente el texto más importante del Nuevo Cine que trató este asunto es Dialéctica del espectador de Tomás Gutiérrez Alea, en el que su autor problematiza la transformación que la audiencia a quien va dirigido el filme, debe experimentar al enfrentarse a las películas que pertenecen a esta nueva corriente cinematográfica y revisa los atributos del cine que promueve este cambio:

El cine será más fecundo en la medida en que empuje al espectador hacia una más profunda comprensión de la realidad y consecuentemente, en la medida en que lo incite a dejar de ser un mero espectador ante la realidad. Para eso, debemos apelar no sólo a la emoción, al sentimiento, sino también a la razón, al intelecto (Gutiérrez Alea, 1983: 36).

El Nuevo Cine Latinoamericano postuló no sólo una audiencia que al definirse como tal se convirtiera en agente de cambio social en un sentido amplio, sino que en un sentido más localizado, se volviera ella misma productora de un discurso artístico. La sociedad ideal, la socialista, triunfante tras los procesos echados a andar en ese entonces, sería la que promovería el desarrollo de las potencialidades de todos los miembros de la comunidad; una vez en igualdad de condiciones no serían necesarios los artistas, porque cualquiera podría ser uno. En ello coincide también Littin, en el texto del "Primer Acuerdo del Manifiesto Político de los cineastas de la Unidad Popular”:

El pueblo no necesita intermediarios ni una clase especial que lo interprete. Si bien esta respondestar un

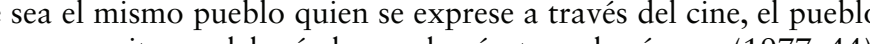

que antes tuvo en sus manos una guitarra, deberá al

Esta utopía cultural está muy bien desarrollada en el texto Por un cine imperfecto, de Julio García Espinosa, que también analiza los conceptos de la cultura popular y la cultura de masas, sobre los que volveré más adelante. Pero, volviendo al punto anterior, el cine al que se aspiraba era el que pudieran realizar todos los individuos en una sociedad igualitaria y justa. Sin embargo, en el camino a esa tierra prometida, los filmes debían despertar las conciencias dormidas, y ése era su aporte a la construcción de esta colectividad ideal.

En una segunda aproximación, el rol del espectador es asimismo relevante en el Manifiesto de los cineastas de la Unidad Popular, que el propio Littin (junto a Sergio Castilla) redactó. En la declaración N 10 -de un total de trece- se lee lo siguiente: "Que no existen filmes revolucionarios en sí. Que éstos adquieren categoría de tales en el contacto de la obra con su público y principalmente, en su repercusión como agente activador de una acción revolucionaria" (Orell García, 2006: 124). De lo anterior se desprende la importancia de un público que ponga en funcionamiento el potencial renovador de una cinta. Sin su mirada, sin su juicio, sin su participación como espectador/actor, el filme pierde su carga transformadora. Aquí estamos frente a un acercamiento que se plantea en otro sentido, aunque esté dirigido a un mismo fin: el de la liberación. Si "no existen filmes revolucionarios”, no es la película la que soplará su aliento reformador sobre la audiencia, sino que es la audiencia, el público, el que activará cada filme hacia su potencial de cambio. Más cercano a los postulados que más tarde desarrollará la Teoría de la Recepción o Christian Metz en El significante imaginario, que reconocen en el receptor un poder de activación de sentido de la obra, pero siempre en los territorios del compromiso político, esta postura declarada en el "Manifiesto" se emparenta también con lo señalado por el propio Littin en una entrevista para la Revista Cine Cubano: "creemos que el más grande revolucionario es el pueblo y creemos que el pueblo no tiene nada que aprender de nosotros, al contrario, nosotros tenemos que aprender de ellos, y ésta es una cosa muy importante" (1977: 21).

Hay un tercer aspecto que quiero destacar, a fin de hacer un cruce con lo ya expuesto, una de las peculiaridades de la película en cuestión es su éxito con el público. Además del reconocimiento de la crítica, dentro y fuera del país, se trató de un filme que podemos catalogar de "popular", no en el sentido de un arte representativo del pueblo sino en el de "masivo". Es también interesante que, a diferencia de otras realizaciones comprometidas políticamente, su contexto de distribución posea una inscripción doble. Un ejemplo radi- 
cal, como el de La hora de los hornos, filmada bajo condiciones de alto riesgo, en plena dictadura, y proyectada en espacios alternativos, contrasta con el caso de El Chacal. Esta última tiene, como dije, dos escenarios de distribución; por una parte el que podemos llamar "alternativo", pero que a diferencia del peligro y la urgencia que caracterizan al documental de Getino y Solanas ${ }^{11}$, se inserta en la campaña presidencial de Salvador Allende. Las manifestaciones solían acompañarse de proyección de películas, y este ambiente proselitista pero, sobre todo, celebratorio, es el que enmarca las proyecciones. Los asistentes son, en su mayoría, trabajadores de clase media y baja, mezclados con intelectuales de izquierda, que no deben pagar por acceder a una muestra de cine en espacios improvisados. Por otra parte, El Chacal se exhibió también en salas de cine normales y tuvo allí un notable éxito. En este último caso, su audiencia es la clase media-alta, profesionales de clase media, quienes por medio de una entrada pagada, pueden obtener una hora y media de proyección en un local especialmente adecuado para ello.

En Dialéctica del espectador, Gutiérrez Alea distingue dos acepciones de lo que llamamos cine popular. En un sentido, se refiere al cine masivo, al que "logra atraer a un público indiferenciado, mayoritario y ávido de ilusiones" (24); y en otro, al que representa a los sectores más oprimidos y explotados de la escala social, "un cine que además exprese los intereses más profundos y más auténticos del pueblo y que responda a ellos”(29). Con otra nomenclatura, pero aludiendo al mismo fenómeno, García Espinosa, en Por un cine imperfecto, diferencia el "arte de masas" de el "arte para las masas". Este último es el que desarrolla una minoría para una masa que sólo aspira al rol de espectador y consumidor, mientras que el primero es el que es efectivamente llevado a cabo por la masa activa, e pueblo, pero que sólo puede tener lugar en una sociedad igualitaria. Por el momento, el cine comprometido es el que facilitará la toma de conciencia de esa masa adormecida y entregará las herramientas para la acción. Podemos decir que El Chacal de Nahueltoro fue masiva en estos dos sentidos, y aunque su fin único era el de promover un cambio social, me gustaría explorar de qué manera se expresan en el filme estas dos posiciones, al menos aparentemente, contradictorias. Ya el punto de partida teórico de los tres directores encierra una contradicción que es interesante problematizar. Si el rol fundamental de este nuevo cine era el de mover a la autonomía, a la liberación de este cuerpo colectivo: ¿cómo es posible hacerlo en el campo del adoctrinamiento, de la pedagogía? ${ }^{12}$; ¿Cómo desprendernos de la paradoja del "escuchar al pueblo" pero no darle voz sino intermediarios? Según los planteamientos que he revisado, el pueblo no podrá ejercer su derecho propio a la expresión artística mientras no se complete el proceso que lleve a la instauración de un régimen igualitario. Para alcanzar esa meta, el pueblo debe aprender de la élite intelectual cómo hacerlo. En el caso del Chacal, de José del Carmen Valenzuela Castillo, su inserción en la cultura, su conquista del rango de hombre civilizado fue su condena. Sólo la educación y la integración social le otorgaron conciencia de su propio crimen y de la vida injusta que había tenido, pero no por eso dejó de ser sentenciado. En este sentido, José del Carmen, como representante de una clase desposeída y marginada, perteneciente al peldaño más La Hora de los Hornos, producción cinematográfica argentina de 4 horas de duración, fue prohibida en su
momento, distribuida ilegalmente y difundida en cine-club e instancias improvisadas de proyección. Las partes que conforman la película fueron exhibidas indistintamente, todas juntas, por fragmentos, en diferente orden, según el contexto en que se mostraran.

En su libro, Dialéctica del Espectador, Gutiérrez Alea se hace cargo de esta contradicción preguntándose cómo es posible reafirmar el contexto revolucionario y a la vez instalar la crítica. La respuesta está en su filme Memorias del Subdesarrollo. bajo de la escala social, inmerso en la ignorancia y el desamparo más absoluto, recibe educación y es aceptado por la cultura sólo para castigarlo. La contradicción más evidente es la que nos muestra que la mejor vida que se le ofrece a José es la que tiene en la cárcel. Las herramientas de liberación (la educación, la religión) son parte del mismo sistema, la misma organización que prepara y ejecuta (con precisión y pericia) su fusilamiento.

He escogido para comenzar lo que corresponde a la presentación de títulos de crédito, en la que la película se sitúa a sí misma en determinado registro. Indagar en este posicionamiento es lo que me propongo hacer en una aproximación inicial por su pertinencia con el tema que trato. Más adelante, me propongo examinar los mecanismos de identificación que se despliegan en la segunda parte de la película (la que se ha reconocido como de estilo más convencional y más arraigada en los terrenos de la ficción), en cuanto la mayor parte de las técnicas de distanciamiento se suspenden aquí en pos de una representación de los hechos más tradicional, y analizar en qué medida esta decisión se enfrenta a la opción estilística de la primera parte.

\section{LAS DOS CARAS DE LA MULTITUD}

Como ya adelanté, consideraré que la presentación de créditos de esta película, si bien no es en estricto rigor parte de la "historia" que se pretende poner en pantalla, entrega ciertas señales acerca del filme en sí mismo, y de cómo quiere éste ser recibido. Es de alguna forma, el acto de saludo de la cinta ante su audiencia. En el caso de El Chacal, varios elementos llaman la atención. El primero de ellos, a la vez que evidente es enigmático, es de corte visual. La película se inicia con un fondo completamente negro y sobre él, letras que detallan las fuentes de información sobre las que se sostiene la narración, pero poco a poco, del fondo negro comienzan a emerger manchas blanquecinas de las que muy lentamente, a través de planos fundidos en los que la cámara se aleja gradualmente, va surgiendo una imagen -aunque con dificultad- reconocible. No es sino hasta 1:50 minutos que puede distinguirse la aparición de un rostro en un blanco y negro exageradamente contrastado. Es en este momento cuando notamos que las letras de créditos han estado insertas en lo que corresponde a la boca de la figura, es como si salieran de su boca. Con este detalle se insinúa que la historia, los hechos narrados, la película misma, sale de la voz de ese individuo (una mujer): la voz del pueblo es la que da cuerpo a esta ficción-documental. Sin embargo, las letras contienen los nombres de los realizadores y han sido puestas por el equipo encargado de la postproducción, son ellos quienes ponen estas palabras en su boca, y he aquí otro indicio de la ambigüedad de un discurso que pertenece y no pertenece a quien lo genera. Diez segundos más adelante surge un segundo rostro junto al primero y desde ahí hasta el fin de los créditos vemos solamente definirse esta misma imagen, siempre gracias a la ampliación del campo de visión. Ya en los últimos segundos de la presentación es cuando los rostros aparecen contextualizados en lo que parece ser una multitud.

El relato se inicia con la detención del homicida y una turba de gente que lo espera a la salida del recinto penal, desde donde será trasladado a la reconstitución de escena. Entre la muchedumbre -registrada a través de una cámara en mano excesivamente móvil, en la que abundan los planos medios que por momentos pierden el encuadre y no consignan más que su propio zigzagueo- podemos reconocer los rostros de las mujeres de los créditos. Esta multitud está reunida aquí para pedir el ajusticiamiento del criminal, una costumbre 
todavía en práctica en Chile en casos particularmente aberrantes como violaciones de niños $\mathrm{o}$ asesinatos en serie. Lo que me parece interesante es que la imagen que se revela en los créditos apela a la estética del afiche militante. La escuela del arte callejero del mural y el afiche proliferaron en estos años. Los rostros de las mujeres (una de ellas gritando, la otra con expresión de aflicción) podrían muy bien equipararse a la de las carátulas de grupo musicales comprometidos políticamente o ciertos murales realizados por pobladores. La tipografía, junto a la imagen, se engarza también en esta tradición del afiche de fines de los sesentas; en efecto, los títulos están a cargo de los hermanos Vicente y Antonio Larrea, reconocidos en el período por su trabajo en el sello discográfico DICAP (Discoteca del Cantar Popular) que marcó el estilo de la gráfica en el período. La imagen de los créditos y el afiche comparten una estética común, ya que el contraste luz/sombra que se observa en la secuencia de la película, se asemeja al de la serigrafía, uno de los procedimientos utilizados para la fabricación de afiches, o a la matriz del stencil, hoy muy usada en grafitti urbano.

El punto conflictivo que quiero destacar es que las figuras humanas que encontramos en este tipo de arte popular representan al pueblo oprimido/levantado contra la opresión burguesa o latifundista. Por el contrario, las mujeres que vemos manifestándose en las imágenes de los créditos iniciales, lo hacen en contra de una de las víctimas de ese sistema abusivo. En la película, el asesino es mucho más un mártir que un culpable, su figura debería ser análoga a la de las mujeres sufrientes en la secuencia de créditos y sin embargo, estas mujeres son en realidad, el pueblo, la masa sin conciencia de clase, que se alía con los grupos de poder para avalar, e incluso exigir, el castigo. Digo que es interesante porque estos personajes desarrollan entonces una doble significación: la de la masa acrítica que a exige castigo al chivo expiatorio, y por otro lado la del pueblo oprimido al que el mismo protagonista pertenece. Siguiendo los planteamientos del propio equipo realizador, esta doble inscripción podría ser la de la transformación que la audiencia -el pueblo- debe sufrir luego de presenciar una película que, lejos de entretener, debe despertar las conciencias. Para Littin, el cine revolucionario es aquél "capaz de motiva y activar a su público" y esta cinta: “" tierra en Chile, de la Reforma Agraria, de los marginados, de la aplicación de la justicia, de los valores morales que rigen la educación nacional y, por fin, de la libertad" (Owen Silva, 2008). Pero también es posible leerlo como la ambivalencia latente de esa masa, que bien puede ser malformada y demolida, convertida en verdugo de uno de sus pares, como alertada en su conciencia de clase y por ende, liberada. En el retrato de las dos mujeres, utilizado y estilizado en la secuencia de créditos, queda en evidencia esta declaración de intenciones, pero también la complejidad y multidimensionalidad de esa muchedumbre que en la época se catalogara como pueblo.

El guión de la película incluye una dedicatoria que no aparece en el filme. Dice: "A Jovina, Alicia, Judith, Rosina, Rosa, José del Carmen. Condenados de la tierra". En clara alusión al libro de Frantz Fanon, Los condenados de la tierra, la referencia pone en un mismo nivel a las cinco víctimas del Chacal y al mismo victimario. La famosa obra de Fanon -autor que fue un referente constante para el Nuevo Cine Latinoamericano y su crítica postcolonialista- denomina "condenados de la tierra" no al proletariado definido por Marx, sino más bien a un sector aún más marginal, ajeno a los cambios de la producción industrial, se trata de los campesinos pobres asentados en las zonas rurales. Son ellos, con su energía autónoma, los más indicados para realizar el proceso revolucionario. José del Carmen, el Chacal, junto a sus víctimas y todos aquellos a quienes representa su figura, son los condenados, el pueblo al que Littin dice querer escuchar. ¿Quién es entonces la multitud que reclama su muerte?; ¿Quiénes las mujeres que se levantan y alzan la voz en la presentación de títulos?

En otros momentos del filme encontramos otra vez a la multitud que exige castigo para el criminal: tras su apresamiento, en la reconstitución de escena, en el fusilamiento. En las dos primeras, el manejo de la cámara es muy similar al de la primera escena (la que muestra a las mujeres convertidas en íconos de lucha popular): cámara en mano, análoga a la del reporteo periodístico, que se inmiscuye, se mezcla, se entromete en la muchedumbre, imitando también el ojo curioso de la masa, pero a la vez indagándola a ella misma. Sólo al final, en la escena del fusilamiento, podemos ver una multitud ordenada, en un plano general, pero representada sólo por la prensa y la oficialidad, por los periodistas autorizados y funcionarios ligados al proceso. Tras los disparos, se escucha la voz dolorosa de una mujer: "¡Está vivo!”, inmediatamente sobreviene la confusión y otra vez la cámara -como en los planos anteriores que retrataban a la multitud- que pierde el encuadre entre los forcejeos del grupo humano y se escucha la voz del periodista-personaje: “iAsesinos!”. El cambio de actitud ha tenido lugar, pero también ha habido un cambio de individuo: en la primera escena tenemos a las mujeres de clase media-baja confundidas entre otros tantos como ellas; y en la última, al periodista, perteneciente a la minoría educada, distinguido e identificable a través de toda la película. Littin, mientras se dedicaba a la realización de la película, trabajó en televisión, conoció entonces muy de cerca el trabajo de los reporteros y otros profesionales ligados a la información. Por lo demás, el trabajo de registro y difusión del material, es análogo al que la película misma realiza. En ese sentido, veo en el periodista una versión del propio Littin, que se arroba el derecho a representar a esa masa ilocalizable del inicio. El punto es que la multitud es, en un primer nivel, caótica, desorganizada, informe; en cambio, el pueblo es, en un segundo nivel, una agrupación que se ordena, se regula, se domina (a través del plano general que nos muestra al grupo de periodistas, e incluso a través del "afiche" de los créditos). Pero será siempre un pueblo nombrado y representado por otros: en este caso, su figura estilizada en el poster de propaganda o la voz mediática del reportero.

\section{LOS ARTIFICIOS DE LA IDENTIFICACIÓN}

Ya vimos que la película puede dividirse en dos partes y que la diferencia entre ambas es clara. Desde la narración de la infancia a través del registro de documentos legales, hasta su reclusión en la cárcel de Chillán, el filme se desarrolla utilizando las técnicas del documental que mencioné al principio, y combinadas con las propias del argumental. En los momentos en que la ficción parece tomar las riendas de la primera parte, la inclusión de estos recursos documentales o el innovador trabajo de montaje, producen el efecto de distanciamiento en el espectador, y evitan sostener la ilusión de realidad del filme, y recordándonos que estamos frente a una pantalla: "de manera que el espectador no se entrega plenamente, conserva la lucidez y el sentido crítico" (Gutiérrez Alea, 1983: 56).

Marcaré el tránsito a la segunda parte del filme con la escena del ingreso de José a la cárcel de Chillán. Este plano subjetivo es el primero de la película en el que se señala cinematográficamente la mirada del protagonista. ${ }^{13}$ Con un plano secuencia de 42 segundos, 
compartimos con José su visión de la entrada al centro penitenciario: las puertas abiertas por los gendarmes, las familias de visita a la entrada, las frases escritas en las paredes del recinto ("La Redención por el Trabajo", "Redimir No Deprimir"), los demás presos. En la sección anterior, habíamos tenido acceso al punto de vista del personaje a través del relato oficial del proceso, puesto en escena por medio de su voz. A pesar de que el tono de José puede ser descrito como plano o sin matices, esta característica no tiene que ver con una contención en la técnica de actuación, si no por el contrario, con la apropiación por parte del actor, de un personaje que en la vida real aparecía como desmotivado, apático, desganado. Sin embargo, este relato está siempre ilustrado por las escenas que utilizan un estilo de recreación documental, y que en este sentido, quiebran el espejismo de la ficción. Es interesante que, si bien es el documental el que se plantea como más apegado a la realidad misma, no intenta sustituirla, y es por esto que en sus recursos más propios, nos recuerda siempre que estamos frente a una reproducción de la realidad. Por el contrario, las técnicas narrativas del argumental proponen un simulacro, que aunque puede tener asidero en la realidad, se toma la libertad de ofrecer al espectador un pacto en el que superponemos esta realidad para suspender por un instante la otra, y así gozar de la ilusión.

El Nuevo Cine Latinoamericano renunció a las trampas de dicha ilusión en pos de un cine que despertara a la audiencia y la pusiera en alerta ante el artificio de la imagen proyectada. Así, el peligro del pacto con la ficción es que cancela en gran medida el potencial crítico del espectador, cuando lo sumerge en una suerte de fantasía hipnótica y se vuelve una realidad paralela que no se conecta con el exterior más que en su valor "estupefaciente". En Dialéctica del espectador, Gutiérrez Alea analiza también este fenómeno y examina los aportes de Bertolt Brecht al cine en este período. Su teoría del distanciamiento, fundamenta para el teatro contemporáneo, fue utilizada también por los cineastas de este movimiento. Dicho recurso permite apelar a las facultades de raciocinio y juicio en una audiencia que se mantiene despierta y atenta a los mecanismos del discurso fílmico. El distanciamiento pone en evidencia el artificio, el hecho de que hay un alguien representándolo y tomando decisiones; rompe la ilusión, sorprende, interrumpe. Este tipo de arte se enfrenta, entonces, a la identificación pasiva, que se desarrolla en un nivel inconsciente y mantiene al espectador como un mero receptor de esos contenidos. En su libro, Gutiérrez Alea cita a Brecht:

Hay que cambiar el teatro en su totalidad: los cambios no deben alcanzar sólo el texto, el actor o toda la representación escénica... también el espectador debe entrar en el proceso. Su actitud debe ser modificada. Apela más a la razón que al sentimiento de los espectadores y llama la atención sobre el hecho de que "el espectador no debe identificarse con los personajes, sino discutirlos", para lo cual propone un mecanismo de alienación o enajent la relación del espectador con el personaje (70).

Se han realizado numerosos estudios que establecen relaciones entre los procesos psí quicos y la experiencia cinematográfica. Acerca de la identificación, Cristián Metz vinculó lo que Freud denominó identificación primaria y el estadio del espejo descrito por Lacan -ambas etapas narcisistas en las que el sujeto se constituye en la imagen externa- con el

tivo. Se trata de la escena en la parroquia, en la que José del Carmen, niño, es llevado donde el párroco luego de ser recogido por los policías. Sin embargo, en esta escena se combina el plano subjetivo con el objetivo, de acto mismo de contemplación de la pantalla, instancia en la que cada individuo -que en este contexto no es el individuo de carne y hueso, sino el espectador construido por el filme- se reconoce en la imagen como un puro acto de percepción (Stam, 1992: 151). Pero no es este nivel de identificación el que nos interesa aquí, sino la identificación secundaria, que no es lo que comúnmente se conoce como empatía: "yo sé cómo te sientes", sino que: "yo veo lo que tú ves, desde tu posición” (Stam, 1992: 151). Aunque no se trata de una posición fija o estable, sino que la identificación funciona como un cambio de posiciones permanente, que se traslada desde uno a otro personaje y desde uno a otro punto de vista. En este sentido, no hablamos de un espectador definido por su pasividad, por el contrario, la inmovilidad de su butaca es a la vez una agitación psíquica permanente, pero que no se corresponde con la agitación política promovida por el Tercer Cine o el Cine Imperfecto o de la Liberación.

Ahora veamos cómo funcionan estos conceptos en El Chacal de Nahueltoro. Tal como he descrito, la primera parte se apega bastante a los mecanismos de distanciamiento propuestos por Brecht, y por ende a la estética renovadora del Nuevo Cine Latinoamericano que impulsó la creación de una audiencia activa y crítica. Sin embargo, en la segunda parte, que como ha señalado, se iniciaría con el plano subjetivo de la entrada del criminal a la cárcel, predomina una narrativa más tradicional que propicia la identificación tal como la he definido más arriba. No sólo un estilo más convencional que se apega en mayor medida al canon de la ficción, sino que la actuación de Nelson Villagra -elogiada en numerosas ocasiones por su compenetración con el personaje- es uno de los atributos que destaca en el filme. Su trabajo se enmarca en la actuación a la manera de Stanislavski ${ }^{14}$, en la que el actor se involucra internamente en su representación. Durante los casi tres meses que duró el rodaje, Villagra se vistió con las ropas del fusilado, mantuvo su forma de caminar y su lenguaje, convivió con presos y campesinos para aprender y comprender sus posturas y actitudes. Dentro de los métodos del distanciamiento, el trabajo del actor no queda fuera del proceso total. De esto Littin sabía bastante, ya que antes de dedicarse al cine y la televisión había estudiado teatro. En efecto, su trabajo de dirección de actores para esta película fue un aspecto vital en la consecución del total (Orell García, 2006: 153). Sin embargo, en lugar de trabajar el distanciamiento, aplicó con Villagra el de la interpretación realista.

Ana M. López ha indicado que en esta segunda parte, es el punto de vista del periodista el que predomina, en contraste con la primera parte en la que se privilegia el de José (416). Ya he señalado que, si bien en la primera parte es el relato del condenado el que sostiene en buena medida la narrativa del filme, cualquier tipo de identificación se clausura o se suspende en virtud de los experimentos estilísticos que el director emprende en esta sección. Lo que yo postulo es que en la segunda parte, inaugurada por el plano subjetivo, es la mirada de José la que se revela y que viaja desde su propia experiencia con la integración a la sociedad y posterior expulsión de la misma, a la del periodista testigo que desarrolla empatía con el condenado y se compromete con esta mirada, para al final gritar: "iAsesinos!”, pero en ningún caso morir por él. En términos prácticos, la labor del periodista no es determinante para el destino de José. Su pronunciamiento a través del grito lo autolibera de la culpa que una sociedad injusta, en la que él es uno de los privilegiados, le provoca. Pero su gesto no es el que conduce el cambio.

4 El método Stanivslaski introdujo en su época una técnica de actuación que se conoce como realismo psicológico y que implica la búsqueda emocional interna por parte del actor, para dar con una actuación verídica, realista y vivencial. 
En Dialéctica del espectador, Gutiérrez Alea establece un paralelo entre los postulados de Brecht que ya he revisado y los Eisenstein. En relación a la identificación, el director ruso sí reconoce este proceso como un elemento útil y favorable para la causa revolucionaria. Esto, en la medida que Eisenstein, a diferencia de Brecht, valora el aspecto emocional como herramienta válida de compromiso político:

Para Eisenstein ese momento en que el espectador se enajena de sí, deja de ser él mismo para

Para Eisenstein ese monent vivir en el otro -en el personaje- revistió especial interés, en tanto constituye la premisa de el ámbito del sentimiento, de lo emocional; en estado de éxtasis (69).

Gutiérrez Alea entendió estas diferencias entre ambos teóricos atribuyéndolas principalmente a los contextos socio-políticos que les tocó vivir. Eisenstein inserto en los primeros años de la revolución, tiempos de "exaltación, de fuerza naciente, de triunfo, de afirmación, de identificación emocional” (74), mientras que encontramos a Brecht en plena crisis económica en el fracaso de la revolución, el posterior ascenso del fascismo. Si aplicamos esta matriz al en el fracaso de la revolución, el posterior ascenso del fascismo. Si aplicamos esta matriz al
contexto de El Chacal, éste corresponde al de Eisenstein, a los años del fortalecimiento de la izquierda, las organizaciones populares, años de cambio social en Chile, el advenimiento del primer gobierno socialista. Sin embargo, la identificación que opera en este filme no es en ningún caso la de la épica (en el sentido eisensteniano, no brechtiano), sino que se inserta en un cuadro de abandono y miseria, de injusticia sin redención ni rebelión. ¿Dónde se inscribe entonces la fábula real del Chacal de Nahueltoro? A pesar de los intentos de la primera parte por sacarla de los registros de la tradición e invocar un discurso renovador, el retrato fílmico de José del Carmen sigue ubicándose donde la comunidad lo pusiera luego de su fusilamiento; en el espacio del santo, del milagrero, del mártir ${ }^{15}$. De hecho, el distanciamiento de la primera parte es útil a una mirada desinvolucrada en los hechos del crimen, posición que se vuelve ventajosa a la hora de proponer la identificación con el criminal en la segunda parte. La película no profundiza demasiado en el aspecto religioso (aunque el sacerdote sea uno de los personajes principales y José del Carmen se convierta: "Ya no me matarán, ahora soy católico"), pero posiciona a su protagonista en el lugar no del héroe, sino del sacrificado del que injustamente recibe castigo y no tiene salvación más que en la promesa de otra vida. En este sentido la película, más que cuestionar el mito, lo refuerza, no sólo en cuanto a su contenido sino también en cuanto al estilo que se privilegia en la segunda parte y que, como señalé, neutraliza los experimentos formales de la primera, poniéndolos al servicio de la identificación que se desarrolla después. De esta manera, entrega al pueblo su espejo de redención ilusoria (morir con él) y al burgués su espacio de liberación de conciencia (gritar: "iAsesinos!").

Esto es, sin embargo, coherente con la opción, como diría Littin, de "escuchar al pueblo", y es la que construye, junto a la multitud caracterizada en la presentación de créditos y en la primera escena, una representación ambivalente de este conglomerado: el pueblo levantado es el mismo pueblo reaccionario; los condenados de la tierra, la fuerza generadora de cambio es el pueblo sin salvación. Lo complejo es que, en un cine que se propone como motor de transformaciones sociales, la figura del mártir es incongruente. El mártir, que debe morir, debe sufrir, no supone una modificación de su situación, lo contrario implicaría la pérdida de su identidad como tal.

Tras su muerte y hasta hoy, José del Carmen se convirtió en una figura mítica, cuya tumba conserva todavía

las placas de agradecimiento por los favores concedidos.
En la película parecen haber dos estadios de lo que se ha llamado el pueblo. El primero, representado por la multitud caótica, inasible, la multitud ambivalente que puede contener tanto la ideología del patrón como la de sus liberadores, pero a cuya transformación sólo asistimos a través del personaje representante de la élite intelectual comprometida; y otro, el nivel de pueblo propiamente tal, el grupo articulado pero que no es en verdad la masa misma, sino sus intermediarios. En un tercer nivel, que se presenta en un registro totalmente al margen de los antes señalados, tenemos a la población más marginal, los condenados (José del Carmen y sus víctimas), cuya cultura y punto de vista son revisadas por el filme, pero no para entregarles una salida a su marginalización. La entrada en la cultura no sólo no salva al protagonista, sino que aparece como un reforzamiento de su docilidad y sumisión. Ellos no tienen voz más que a través de otros (el registro documental es el del materia judicial y el de las entrevistas) y su discurso no los llevará a la liberación sino a la muerte.

Quiero poner atención en una escena de la película que ejemplifica aún mejor el desamparo del condenado. Este fragmento (cuyo análisis daría para entrar en nuevos planteamientos de tipo psicoanalítico acerca del filme) es el que sugiere, apenas esboza, las motivaciones del crimen. En conversación con el sacerdote, José del Carmen le relata parte de su infancia. En este relato, vuelve sobre un detalle que ya había expuesto antes: tras la muerte de su padre, su madre se puso a vivir con un hijastro, y él, al volver a la casa, luego de vagabundear durante años, se encuentra con que ella ha tenido dos hijos más con este medio hermano suyo. "Cuando cometí lo que... cuando hice lo que hice...". No quiero entrar en lecturas más profundas de sus motivaciones (la figura de la madre es un referente sospechosamente recurrente en su discurso), sino que hacer notar el contraste entre esta confesión a medias y la escena inmediatamente siguiente: carcajadas y ebriedad de lo que parece una fiesta, los rostros de mujeres enjoyadas y hombres de cuello y corbata, ríen desaforadamente, como burlándose. Uno de ellos es el periodista. Este inserto, fugitivo y confuso como las irrupciones de la máquina inconsciente en los espacios de la cotidianeidad, sugiere una vuelta de tuerca más en la lectura del filme. No sólo el periodista no puede ser la voz del condenado sino sólo traducirla (gritar "¡Asesinos! en lugar de morir); además tampoco estará de su lado porque sus pares son otros, y las motivaciones del crimen están tan lejos de su esfera como el campo estéril lo está de la fiesta.

El Chacal de Nabueltoro ejemplifica muy bien un asunto ya de por sí problemático, el de cómo conciliar el adoctrinamiento de las masas con su autonomía. Aquí vemos también enfrentarse los diversos niveles en los que se representa a la multitud y de qué manera su estadio final es el que la sistematiza y la denomina (pueblo) para cumplir con los lineamientos de un sistema que continúa siendo desigual y que no cumple con su meta de representación legítima. En este escenario, un residuo marginal permanece siempre en los bordes, no se integra más que como mito y no obtiene voz propia más que en la mediatización de su discurso.

El periodista, que debiera encarnar ese discurso, supuesto aliado, celebra con sus pares, ríe, bebe y se distancia de una desgracia que no es la suya. José del Carmen debe morir, es el santo, el mártir, el animal de sacrificio, cuya vida eterna, en este caso no está en los cielos, sino en la materia del celuloide. 


\section{REFERENCIAS}

Burton, Jualianne (ed). (1991). Cine y cambio social en América Latina: Imágenes de un continente. México: Diana.

Chanan, Michael (ed). (1976). Chilean Cinema. London: British Film Institute.

Fanon, Frantz. (1963). Los condenados de la tierra. México: Fondo de Cultura Económica.

García Espinosa, Julio. (1979). Por un cine imperfecto. En Una imagen recorre el mundo. La Habana: Letras Cubanas.

Gaudreault, André/ Francois, José. (1995). El relato cinematográfico. Cine y narratología. Buenos Aires: Paidós.

Gutiérrez Alea. (1983). Dialéctica del Espectador. México: Federación Editorial Mexicana. Littin, Miguel. (1977). El Chacal de Nahueltoro/La tierra prometida. México: Universidad Autónoma de México.

López, Ana. (1990). At the limits of Documentary: Hypertextual transformation and the New Latin American Cinema. En The Social Documentary in Latin America. Julianne Burton (ed). Pittsburgh: University of Pittsburgh.

Martin, Michael T. (ed) (1997). New Latin American cinema. Detroit: Wayne State University Press.

Orell García, Marcia. (2006). Las fuentes del Nuevo Cine Latinoamericano. Valparaíso: Ediciones Universitarias de Valparaíso.

Owen Silva, Martín. (2008). El proyecto sociocultural de la izquierda chilena durante la Unidad Popular. Crítica, verdad e inmunología política. Obtenido el 2 de Mayo desde http://nuevomundo.revues.org/index13732.html

Paranaguá, Paulo Antonio (ed). (2003). Cine documental en América Latina. Madrid: Cátedra. Pick, Zuzana M. (1993). The New Latin American Cinema. A continental Project. Austin: University of Texas Press.

Stam, Robert. (1992). New Vocabularies in Film Semiotics. Structuralism, Post-structuralism and beyond. New York: Routledge.

-. (2000). Film Theory. An Introduction. Malden: Blackwell Publishers. 